\begin{tabular}{|l|l|l||}
\hline \multicolumn{2}{|c|}{ PublisherInfo } \\
\hline \hline PublisherName & $:$ & BioMed Central \\
\hline \hline PublisherLocation & $:$ & London \\
\hline \hline PublisherImprintName & $:$ & BioMed Central \\
\hline \hline
\end{tabular}

\title{
Role of TGF? in immune homeostasis
}

\begin{tabular}{||l|l|l||}
\hline \multicolumn{2}{|c|}{ ArticleInfo } \\
\hline \hline ArticleID & $:$ & 186 \\
\hline \hline ArticleDOI & $:$ & $10.1186 /$ ar-2000-66805 \\
\hline \hline ArticleCitationID & $:$ & 66805 \\
\hline \hline ArticleSequenceNumber & $:$ & 143 \\
\hline \hline ArticleCategory & $:$ & Paper Report \\
\hline \hline ArticleFirstPage & $:$ & 1 \\
\hline \hline ArticleLastPage & $:$ & 3 \\
\hline \hline & $:$ & RegistrationDate : 2000-5-2 \\
ArticleHistory & $:$ & OnlineDate \\
\hline \hline ArticleCopyright $2000-5-2$ \\
\hline \hline ArticleGrants & $:$ & Current Science Ltd2000 \\
\hline \hline ArticleContext & $:$ & \\
\hline \hline
\end{tabular}


Sarah Parry, ${ }^{\text {Aff1 }}$

Aff1 Stanford University Medical School, USA

\section{Keywords}

T cell homeostasis, T cells, TGF?, TGF?-receptor

\section{Context}

TGF? is a widely distributed cytokine mediating pleiotropic functions on multiple cell types. Three isoforms of TGF? (1,2 and 3) share a high degree of homology and use the same receptor complex. TGF? 1 is the predominant isoform in lymphoid organs and serum. TGF?1-deficient mice die at 3-4 weeks of age of severe autoimmune responses, apparently due to activated $\mathrm{CD} 4{ }^{+} \mathrm{T}$ cells. Deficiency of either TGF? 2 or -3 results in embryonic lethality. Here, the authors describe a model in which all three endogenously produced TGF? isoforms are blocked selectively in T cells. The strategy involves expression of a dominant-negative form of TGF?-receptor type II (dnTGF?RII), which has a truncated intracellular kinase domain. This molecule binds all isoforms of TGF?, but does not mediate signal transduction. Transgenic (tg) mice that express dnTGF?RII under the control of the murine CD4 promoter were produced. The construct lacks the CD8 silencer and therefore is expressed in both $\mathrm{CD} 4^{+}$ and $\mathrm{CD}^{+} \mathrm{T}$ cells. To investigate the role of TGF? in T cell homeostasis, and its subsequent regulation of autoimmune $\mathrm{T}$ cell responses.

\section{Significant findings}

T cell signaling through the TGF?RII was abolished in T cells but B cell signaling was normal, indicating that the dnTGF?RII was exclusively expressed in T cells. At 3-4 months of age, dnTGF?RII tg mice developed spontaneous autoimmune disease characterized by mononuclear inflammatory infiltration in several organs. Inflammatory bowel disease was prominent and lung, liver, stomach, duodenum, pancreas and kidney were also involved. Serum from 5-month-old mice contained antinuclear antibodies that recognized a variety of nuclear protein extract components, and immune complex deposition occurred in renal glomeruli. Total cell numbers were increased in lymphoid organs of tg mice. FACS analysis revealed decreased numbers of CD62L- ${ }^{\text {hi }}, \mathrm{CD} 44-{ }^{\text {low }}$ naive T cells, but increased numbers of memory $\mathrm{T}$ cells and T cells bearing activation markers CD25, CD69 and CD44. In vitro, activation of $\mathrm{T}$ cells from tg mice and intracellular cytokine staining showed that an increased percentage of dnTGF?RII T cells were capable of both Th1 and/or Th2 cytokine production. This 
indicates that the absence of TGF? signaling enables activation of increased numbers of T cells without polarizing towards either Th1 or Th2 responses. Serum levels of Th2-dependent isotype (IgG1) Th1-dependent isotype (IgG2a) and TGF?/IL5-dependent isotype (IgA) were all increased in the dnTGF?RII tg mice. In contrast, T-cell-independent isotypes (IgM and IgG3) were not significantly increased.

\section{Comments}

Transforming growth factor-? (TGF?) has been implicated in many autoimmune diseases, and appears to be a major product of immunoregulatory $T$ cells in several models of autoimmunity. As a result of the highly pleiotropic properties of TGF?, and the presence of TGF? receptors on a multitude of cell types, defining its role in the regulation of immune responses has been challenging. This paper describes a transgenic model which eliminates the TGF? response selectively in T cells. The autoimmunity which emerges reveals a specific role for TGF? in the homeostasis of autoreactive T cells. As the authors characterize this model further, it will be interesting to learn whether $\mathrm{CD} 4^{+}$and $\mathrm{CD} 8^{+} \mathrm{T}$ cells are equally susceptible to regulation by TGF?, the importance of tissue location in this process, and whether the effect of TGF? applies both to autoreactive T cells and T cells responding to exogenous antigen.

\section{Methods}

The construct encoding the dnTGF?RII was microinjected into C57BL/6xC3H F 1 embryos to generate transgenic ( $\mathrm{tg}$ ) mice. Function of the dnTGF?RII transgene was demonstrated in T cell proliferation assays and by investigating phosphorylation of Smad2, a downstream signaling molecule in the TGF? signaling pathway. Lymphoid and nonlymphoid tissues were examined by standard histological and immunohistological techniques. The differentiation and activation status of $\mathrm{T}$ cells was investigated by FACS analysis for both intracellular cytokines and surface T cell activation markers. Immunoglobulin isotype levels in the mouse serum were measured by ELISA. The presence of antinuclear antibodies in serum was tested by performing a western blot using nuclear protein extract from murine T cells.

\section{References}

1. Gorelik L, Flavell RA: Abrogation of TGF signaling in T cells leads to spontaneous T cell differentiation and autoimmune disease. Immunity. 2000, 12: 655-669.

This PDF file was created after publication. 